\title{
Fatigue as a long-term risk factor for limitations in instrumental activities of daily living and/or mobility performance in older adults after 10 years
}

This article was published in the following Dove Press journal:

Clinical Interventions in Aging

9 November 2016

Number of times this article has been viewed

\author{
Sigrid Mueller-Schotte ${ }^{1-3}$ \\ Nienke Bleijenberg ${ }^{1,2,4}$ \\ Yvonne T van der Schouw \\ Marieke J Schuurmans ${ }^{2,4}$ \\ 'Julius Center for Health Sciences \\ and Primary Care, University \\ Medical Center Utrecht, the \\ Netherlands; ' ${ }^{2}$ epartment for the \\ Chronically III, University of Applied \\ Sciences Utrecht, the Netherlands; \\ ${ }^{3}$ Department of Optometry and \\ Orthoptics, University of Applied \\ Sciences Utrecht, the Netherlands; \\ ${ }^{4}$ Department of Rehabilitation, \\ Nursing Science and Sports, \\ University Medical Center Utrecht, \\ the Netherlands
}

Objectives: Decline in the performance of instrumental activities of daily living (IADL) and mobility may be preceded by symptoms the patient experiences, such as fatigue. The aim of this study is to investigate whether self-reported non-task-specific fatigue is a long-term risk factor for IADL-limitations and/or mobility performance in older adults after 10 years.

Methods: A prospective study from two previously conducted cross-sectional studies with 10-year follow-up was conducted among 285 males and 249 females aged 40-79 years at baseline. Fatigue was measured by asking "Did you feel tired within the past 4 weeks?" (males) and "Do you feel tired?" (females). Self-reported IADLs were assessed at baseline and follow-up. Mobility was assessed by the 6-minute walk test. Gender-specific associations between fatigue and IADL-limitations and mobility were estimated by multivariable logistic and linear regression models.

Results: A total of $18.6 \%$ of males and $28.1 \%$ of females were fatigued. After adjustment, the odds ratio for fatigued versus non-fatigued males affected by IADL-limitations was 3.3 $(P=0.023)$. In females, the association was weaker and not statistically significant, with odds ratio being $1.7(P=0.154)$. Fatigued males walked $39.1 \mathrm{~m}$ shorter distance than those nonfatigued $(P=0.048)$. For fatigued females, the distance was $17.5 \mathrm{~m}$ shorter compared to those non-fatigued $(P=0.479)$.

Conclusion: Our data suggest that self-reported fatigue may be a long-term risk factor for IADL-limitations and mobility performance in middle-aged and elderly males but possibly not in females.

Keywords: fatigue, instrumental activities of daily living, walking, aging

\section{Introduction}

Fatigue is one of the five most common complaints for seeking medical advice in primary care, ${ }^{1,2}$ and is considered to be one of the main features of frailty in older adults. ${ }^{3,4}$ Although fatigue is a known debilitating entity associated with specific chronic diseases, ${ }^{5,6}$ not all patients with fatigue can be diagnosed with an underlying medical condition. ${ }^{7}$ Fatigue significantly burdens the individual's quality of life and is associated with major negative health-related outcomes such as disability and may be a physiological warning symptom of early disability. ${ }^{8,9}$

Maintaining independence in instrumental activities of daily living (IADL) and being able to move around independently in the community is a high priority for older adults. In a study on frailty among older adults, $13.5 \%$ of the non-frail individuals and $59.7 \%$ of the frail individuals reported disability in one or more IADL. ${ }^{3}$ Furthermore, $16 \%$ of the non-frail and $71.1 \%$ of the frail individuals reported impaired mobility.
Correspondence: Sigrid Mueller-Schotte Department for the Chronically III, University of Applied Sciences Utrecht, Heidelberglaan 7, 3584 CS Utrecht, the Netherlands

Tel +3 I 88 48| 5793

Email sigrid.mueller-schotte@hu.nl (c)
hereby accept the Terms. Non-commercial uses of the work are permitted without any further permission from Dove Medical Press Limited, provided the work is properly attributed. For permission hereby accept the Terms. Non-commercial uses of the work are permitted without any further permission from Dove Mediect
for commercial use of this work, please see paragraphs 4.2 and 5 of our Terms (https://www.dovepress.com/terms.php). 
The actual decline may be preceded by symptoms the patient experiences; symptoms not verifiable or visible to the clinician, such as fatigue. ${ }^{10}$

Currently, a golden standard to assess or describe the symptom of fatigue is lacking although multiple tools are available. ${ }^{11}$ Fatigue has many dimensions, however, in the broadest sense it can be described as feeling tired or exhausted by any cause. ${ }^{11}$ Fatigability is the susceptibility to fatigue and in recent scientific literature it has been set out as a perceived inability to continue a standardized activity at the same intensity resulting in a deterioration in performance and some degree of fatigue. ${ }^{12}$ Measures of fatigability by physical activity indicate that the perception of fatigue varies considerably between individuals despite similar levels of activity. ${ }^{8,13}$ Understanding subtle symptoms of the debilitating process at an early stage and at a young age is pivotal to enable timely intervention and possibly prevent or delay disability.

In cross-sectional studies, fatigue was significantly related to poorer physical performance, slower walking speed, lower mobility, and disability in IADLs. ${ }^{14-17}$ Evidence from longitudinal studies with follow-up ranging from 1.5 to 5 years support these findings..$^{9,17-20}$ However, the assessment of fatigue is difficult and varies between studies owing to the subjective nature and multiple dimensions of the symptom (physical, mental, and disease-related). Most follow-up studies evaluated the fatigue level after performance of specific tasks (ie, feeling tired after hair combing) or physical activity (ie, walking), whereas in cross-sectional studies non-task-specific fatigue was assessed by a single or multipleitem questionnaire (eg, feeling tired most of the time in the past month or feeling of having to make an effort to cope with activities of daily living?) which is easily applicable in clinical practice. ${ }^{9,14-16,18,20}$

The aim of this study is to investigate whether selfreported non-task-specific fatigue is a long-term risk factor for IADL-limitations and/or mobility performance in older adults after 10 years.

\section{Methods}

\section{Study design and population}

Data of the PReservation Of Function In the ELderly study (PROFIEL) was used. This is a follow-up study of two previously conducted cross-sectional studies in 402 females (1999-2000, aged 50-74 years at baseline) and 400 males (2001-2002, aged 40-80 years at baseline). ${ }^{21,22}$

Participants were eligible to participate when they were living independently in the community in the middle of the Netherlands and - at baseline - were both physically and mentally able to visit the study center independently. Both studies aimed at identifying determinants of aging and frailty. Extensive information was collected on medical history, lifestyle behavior, somatic, cognitive, functional, and psychosocial status. Inclusion of participants of the follow-up study, PROFIEL, has been described elsewhere. ${ }^{23}$

In short, participants from the two cross-sectional studies who were still alive and not living abroad $(\mathrm{N}=699)$ were re-invited for study participation in the PROFIEL-study between February 2010 and December 2012. In total, 534 individuals agreed to participate (Figure 1). Reasons for declining participation were "feeling physically or mentally not able" $(\mathrm{N}=76)$, "being not interested" $(\mathrm{N}=61)$, or "loss-tofollow-up" $(\mathrm{N}=28)$. All participants gave written informed consent before enrolment in the study. The study protocol was approved by the Institutional Review Board of the University Medical Center Utrecht (METC 09-248).

\section{Measurements}

At baseline and at follow-up, participants visited the study center twice with the exception of 45 individuals who, at follow-up, were examined during home visits due to physical or mental constraints. During these visits, information on age, gender, marital status, educational level, and smoking was obtained. Marital status was categorized into being married or living together, divorced, widowed, and unmarried. Educational level was categorized as low (upper secondary education or less), average (post-secondary non-tertiary education), and high (tertiary or university education) based on the International Classification of Education. ${ }^{24}$

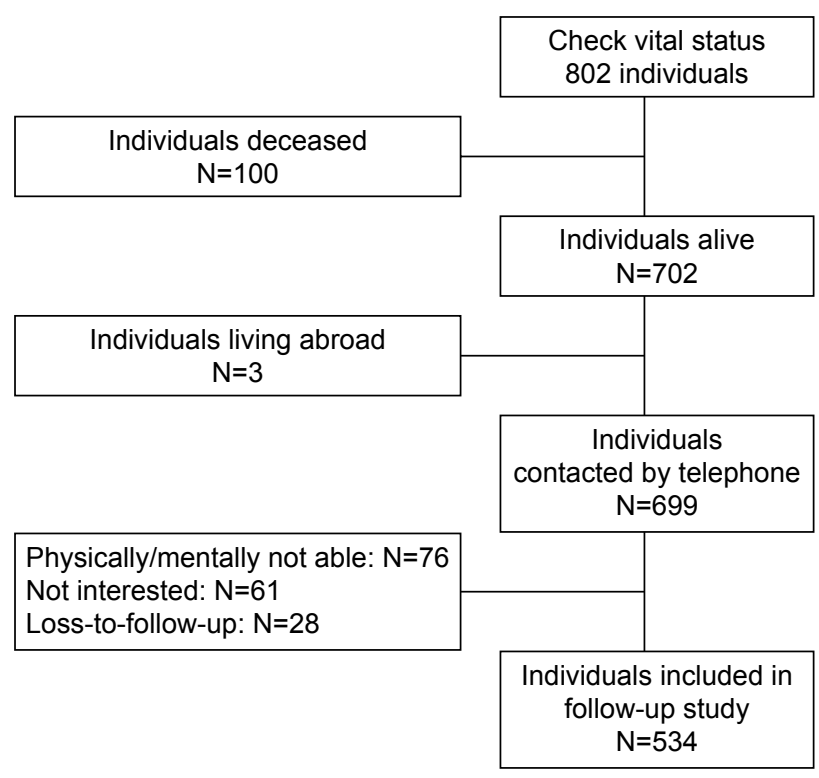

Figure I Flowchart of the inclusion of participants in the middle of the Netherlands. 
Self-reported smoking habits were classified as never, former, or current smoking. The number of chronic diseases was based on self-reported physicians' diagnosis (coronary disease, stroke, hypertension, diabetes mellitus, chronic pulmonary disease, arthritis, hypercholesterolemia, cancer, and hip fracture). Furthermore, height $(\mathrm{m})$ and weight $(\mathrm{kg})$ were measured in standing position with participants wearing light clothing without shoes. Body mass index was calculated as weight divided by the squared height $\left(\mathrm{kg} / \mathrm{m}^{2}\right)$. Cognitive function was assessed using the Dutch version of the MiniMental State Examination (MMSE), a measure of global cognitive function ( $\max$ score $=30) \cdot{ }^{25}$ Lifestyle based on physical activity was operationalized by using the Voorrips Activity Questionnaire for the Elderly. ${ }^{26}$ It includes three domains of physical activities during the preceding year, ie, physical leisure time activities, household, and sporting. At baseline, the total activity score was calculated by summing the three domains of total activities. ${ }^{26}$ The genderspecific percentiles levels of activity were determined. Subsequently, the level of activity was categorized into low activity (lower 33rd percentile), medium activity (middle 33rd percentile), and high activity (upper 33rd percentile).

\section{Determinant}

Fatigue

Since baseline measurements were based on two different cross-sectional studies, the assessment of fatigue varied between males and females. In males, the presence of fatigue was assessed using a question on tiredness of the ShortForm (SF)-36 questionnaire, and in females a question on tiredness of the general history was used. Male participants were asked: "Did you feel tired within the past four weeks?" Answers were rated on a six-point scale, ranging from "all the time" to "none of the time". Subsequently, the answers on the SF-36 questionnaire were dichotomized into "yes" (all the time/most of the time/a good bit of the time) and "no" (some of the time/a little of the time/never). Female participants were asked: "Do you feel tired?" The answer had two categories: "yes" and "no". At follow-up, fatigue was assessed using the question on tiredness of the SF-36 questionnaire in both males and females applying the same coding algorithm as in males at baseline.

\section{Outcomes}

\section{Ability to perform instrumental activities of daily living}

Self-reported IADLs were assessed using the modified Stanford Health Assessment Questionnaire (HAQ) at baseline ${ }^{27}$ and with the modified KATZ-15 ADL/IADL questionnaire at follow-up. ${ }^{28}$ The assessment of IADL at follow-up changed due to participation in an extensive National Program on Aging with a data sharing initiative that chose the modified KATZ-15 questionnaire as the primary outcome of interest. ${ }^{29,30}$ The HAQ consists of 20 questions with four answer categories ranging from "without any difficulties" to "any difficulty" (range: 0-3). Items of the HAQ were dichotomized into "no difficulty" and "any type of difficulty" to perform a task. Six items regarding baseline IADL were used: grooming, use of public transportation, grocery shopping, preparation of a meal, household, stepping in and out of cars. The KATZ-15 questionnaire consists of 15 items with two answer categories: "able to perform (no limitation)" (0) and "unable to perform (limitation)" (1). Eight items regarding IADL at follow-up were used as this was the outcome of interest including: grooming, transportation, grocery shopping, preparation of a meal, telephone use, household, taking medications as prescribed, and managing money. All items were scored and a sum score was calculated. The outcome was measured on a $0-6$ scale for the HAQ, and a $0-8$ scale for the KATZ-15 items, representing the number of IADLlimitations at baseline and at follow-up, respectively; higher scores represent more limitations in IADL.

\section{Mobility}

Walking is a fundamental parameter of human motion and mobility. ${ }^{31}$ The 6-minute walk test (6MWT) measures the distance that an individual can quickly walk on a flat, hard surface in a period of six minutes. It is a valid and reliable test in different patient populations, and easy to administer. ${ }^{32-34}$ Test performance was according to the American Thoracic Society (ATS) guidelines; ${ }^{35}$ personal assistive devices (eg, canes of walkers) were allowed. Each test was supervised by a specially trained research nurse or researcher. After 6 minutes, the total distance walked by the participant in meters was measured. The 6MWT was completed at follow-up only.

\section{Statistical analysis}

Descriptive analysis included calculation of means and standard deviations for continuous normally distributed variables, and medians and interquartile ranges (IQR) for not-normally distributed continuous variables. Frequencies and percentages were used for categorical variables. Due to the gender-specific assessment of fatigue at baseline, all analyses were performed for males and females separately.

Missing data analysis was performed per outcome variable. There were no missing values for the outcome variable of IADL-limitations at baseline or at follow-up for both males and females. A total of 59 males (20.7\%) and 61 (24.5\%) 
females were unable to perform the 6MWT for various reasons; three (1.1\%) males and 14 (5.6\%) females had hypertension and were excluded from the test based on the ATS guidelines, three (1.1\%) males and four (1.6\%) females were unable to perform the test due to health problems, and another two females $(0.4 \%)$ were declined test taking due of a defective monitoring device; a total of $53(18.6 \%)$ males and 41 (16.5\%) females did not perform the test for unspecified reasons. Missing values of the independent variables ranged from $0.2 \%$ to $1.5 \%$. Missing data were imputed by multiple imputation $(\mathrm{m}=5)$ using the statistical program IBM SPSS Statistics for Windows (Version 23.0; IBM Corp., Armonk, NY, USA). The regression coefficients and standard errors of the independent variables were combined from the five datasets using Rubin's rule.

After data imputation, 285 males and 249 females were included in the IADL analysis. For the mobility analyses, participants who were unable to perform the test based on ATS guidelines or disease $(\mathrm{N}=24,4.5 \%)$ were excluded, leaving 279 males and 231 females for analyses.

\section{IADL-limitations}

The association between fatigue and IADL-limitations after 10-year follow-up was estimated using multivariable logistic regression models. The outcome IADL-limitation was categorized into "no limitation" (IADL-limitations $=0$ ) or "any type of limitation" (IADL-limitations $>0$ ) in IADL. In the first models, the crude odds ratios (OR) and their $95 \%$ confidence intervals ( $95 \% \mathrm{CI}$ ) were calculated. In the second models, the associations were adjusted for age and gender. The third models were additionally adjusted for baseline BMI, education, marital status, number of chronic diseases, cognitive status, level of physical activity, baseline IADLlimitation, and follow-up time (months)..$^{6,36-39}$

\section{Mobility}

Linear regression models were used to assess the association between fatigue at baseline and mobility performance, measured in meters walked, after 10-year follow-up. In the first models, the crude estimates were calculated. In the second models, the associations were adjusted for age and gender. The third models were additionally adjusted for baseline BMI, education, marital status, number of chronic diseases, cognitive status, level of physical activity, and follow-up time (months). ${ }^{6,36-39}$ The statistical program IBM SPSS Statistics for Windows (Version 23.0; IBM Corp.) was used for all analyses. Significance levels were set at $\alpha=0.05$ for all tests.

\section{Results}

Table 1 shows the baseline characteristics of the participants stratified by fatigue and gender. Males with symptoms of fatigue were slightly younger than those without fatigue, whereas females with symptoms of fatigue were slightly older than those without those symptoms. Both males and females with fatigue symptoms were less physically active compared to those without fatigue. BMI was similar in both male groups, whereas females with fatigue had a slightly higher BMI than those without fatigue symptoms.

\section{IADL}

Figure 2 depicts the number of participants with self-reported baseline fatigue symptoms stratified by gender and IADLstatus at baseline and 10-year follow-up. Table 2 shows the association between fatigue and IADL-limitation after 10 years. After adjustment, the OR for males affected by IADL-limitations with fatigue was 3.29 (95\% CI: 1.95; 5.55, $P=0.023$ ) compared to those without fatigue. For females with fatigue, the association was less strong and not statistically significant: $\mathrm{OR}=1.65$ (95\% CI: $0.83 ; 3.26, P=0.154)$.

\section{Mobility}

Table 3 shows the association between fatigue and mobility performance after 10 years. At follow-up and after adjustment, males with fatigue at baseline walked 39.12 (95\% CI: -77.83; -0.41) meters shorter distance than those without fatigue which was statistically significant $(P=0.048)$. Females with fatigue at baseline walked at the follow-up $17.46(95 \%$ CI: -67.90; 32.98) meters shorter distance than those without fatigue which was not statistically significant $(P=0.479)$.

\section{Discussion}

The aim of the study was to test the hypothesis if self-reported fatigue is a long-term risk factor for IADL-limitations and/or mobility performance in males and females after 10-year follow-up. This study revealed that self-reported fatigue at baseline is a risk factor for IADL-limitations and mobility performance after 10 years in males, but possibly not in females.

Some methodological limitations must be considered to appreciate the results. 1) We used a single item question to assess self-reported fatigue with different phrasing for males and females as baseline measurements were performed in two gender-specific cross-sectional studies; both aimed at finding determinants of aging and frailty. However, the phrasing was more precise in males, and may therefore account in part for the observed differences between males and females. 
Table I Baseline characteristics of participants stratified by fatigue and gender

\begin{tabular}{|c|c|c|c|c|}
\hline \multirow[t]{2}{*}{ Characteristic } & \multicolumn{2}{|l|}{ Males, $\mathbf{N}=\mathbf{2 8 5}$} & \multicolumn{2}{|l|}{ Females, $\mathbf{N}=\mathbf{2 4 9}$} \\
\hline & $\begin{array}{l}\text { Without symptoms } \\
\text { of fatigue at baseline, } \\
\mathrm{N}=232(81.4 \%)\end{array}$ & $\begin{array}{l}\text { With symptoms } \\
\text { of fatigue at baseline, } \\
\mathrm{N}=53(18.6 \%)\end{array}$ & $\begin{array}{l}\text { Without symptoms } \\
\text { of fatigue at baseline, } \\
\mathrm{N}=179(71.9 \%)\end{array}$ & $\begin{array}{l}\text { With symptoms } \\
\text { of fatigue at baseline, } \\
\mathrm{N}=70(28.1 \%)\end{array}$ \\
\hline \multicolumn{5}{|l|}{ Age (years) } \\
\hline Mean \pm SD & $58.6 \pm 10.8$ & $57.2 \pm 11.3$ & $65.5 \pm 3.7$ & $66.0 \pm 3.8$ \\
\hline \multicolumn{5}{|l|}{ Education, ${ }^{a} \mathrm{~N}(\%)$} \\
\hline Low & $18(7.8)$ & $3(5.7)$ & $50(27.9)$ & $26(37.1)$ \\
\hline Average & $92(39.7)$ & $21(39.6)$ & $87(48.6)$ & $36(51.4)$ \\
\hline High & $122(52.6)$ & $29(54.7)$ & $42(23.5)$ & $8(11.4)$ \\
\hline \multicolumn{5}{|l|}{ Marital status, $\mathrm{N}(\%)$} \\
\hline Married/living together & $209(88.4)$ & 45 (84.9) & I28 (7I.5) & 51 (72.9) \\
\hline Divorced/widowed & $9(3.9)$ & $3(5.7)$ & $35(19.6)$ & $9(12.9)$ \\
\hline Unmarried & $18(7.8)$ & $5(9.4)$ & $16(8.9)$ & $10(14.2)$ \\
\hline \multicolumn{5}{|l|}{ Smoking status, N (\%) } \\
\hline Current or former & I $73(74.6)$ & 45 (84.9) & 89 (49.7) & $30(57.1)$ \\
\hline Never & $59(25.4)$ & $8(15.1)$ & $90(50.3)$ & 40 (42.9) \\
\hline \multicolumn{5}{|l|}{ BMI $\left(\mathrm{kg} / \mathrm{m}^{2}\right)$} \\
\hline Mean \pm SD & $26.2 \pm 3.5$ & $26.0 \pm 3.0$ & $25.5 \pm 4.0$ & $27.1 \pm 5.0$ \\
\hline \multicolumn{5}{|l|}{ Number of chronic diseases ${ }^{\mathrm{b}}$} \\
\hline Mean \pm SD & $0.6 \pm 0.8$ & $0.9 \pm 1.0$ & $1.0 \pm 1.0$ & $2.0 \pm 1.4$ \\
\hline \multicolumn{5}{|l|}{ MMSE score } \\
\hline Median (IQR) & $28.0(2.0)$ & $28.0(2.0)$ & $27.0(2.0)$ & $27.0(2.2)$ \\
\hline \multicolumn{5}{|l|}{ IADL-limitations, N (\%) } \\
\hline No & $210(90.5)$ & $43(8 I . I)$ & I $72(96.1)$ & 61 (87.I) \\
\hline \multicolumn{5}{|l|}{ Activity level, N (\%) } \\
\hline Low & $73(31.6)$ & $21(40.4)$ & $54(30.7)$ & $28(40.0)$ \\
\hline Medium & $82(35.5)$ & $14(26.9)$ & $55(3 \mid .3)$ & $27(38.6)$ \\
\hline High & $76(32.9)$ & $17(32.7)$ & $67(38.1)$ & $15(21.4)$ \\
\hline
\end{tabular}

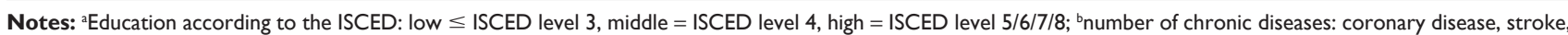
hypertension, diabetes mellitus, chronic pulmonary disease, arthritis, hypercholesterolemia, cancer, and hip fracture.

Abbreviations: BMI, body mass index; IADL, instrumental activities of daily living; IQR, interquartile range; ISCED, International Standard Classification of Education; MMSE, Mini-Mental State Examination; SD, standard deviation.

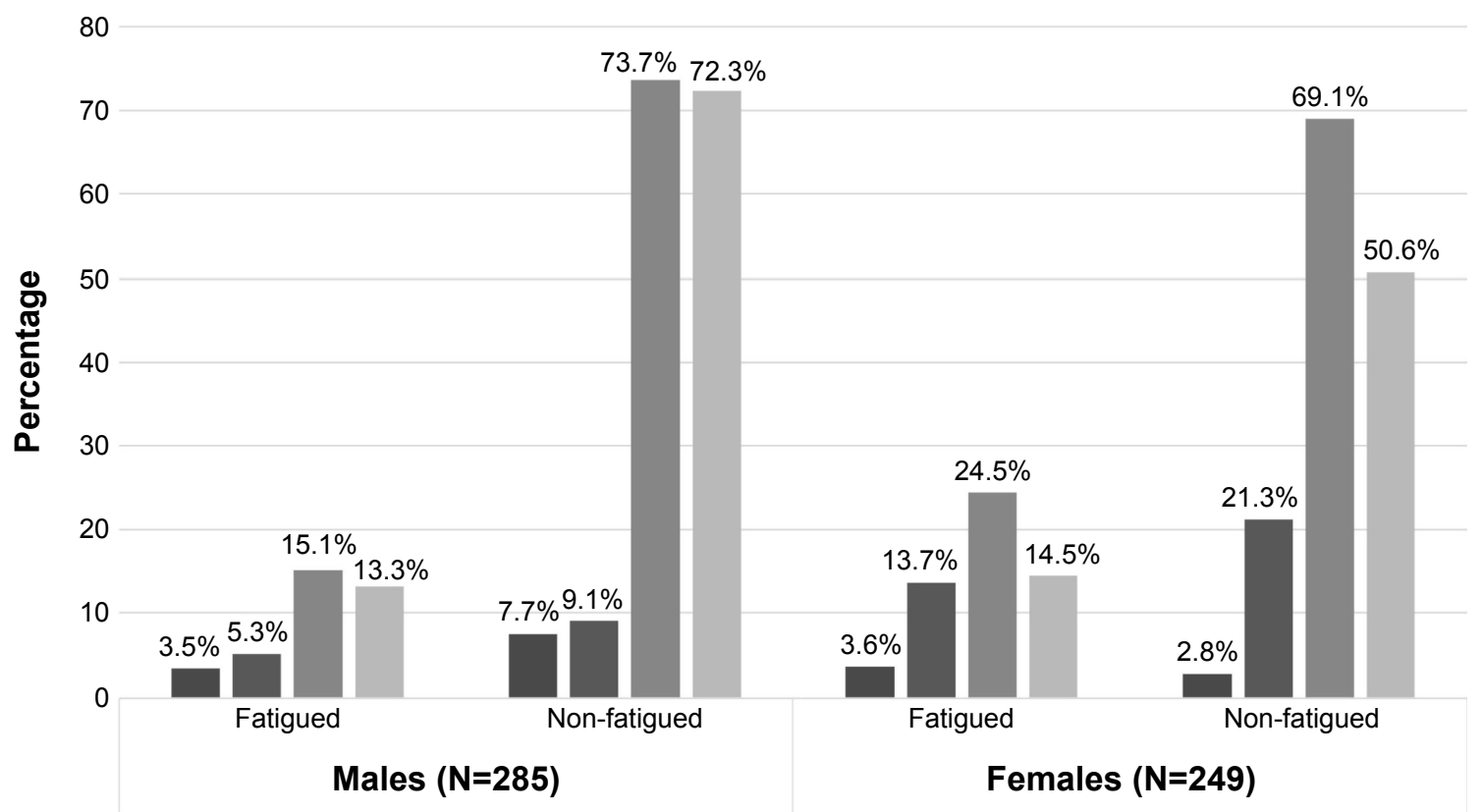

$$
\begin{array}{ll}
\text { IADL-limitations baseline } & \text { IADL-limitations follow-up } \\
\text { No IADL-limitations baseline } & \text { No IADL-limitations follow-up }
\end{array}
$$

Figure 2 Number of participants with self-reported baseline fatigue symptoms stratified gender and IADL status at baseline and I0-year follow-up. Abbreviation: IADL, instrumental activities of daily living. 
Table 2 Association between fatigue at baseline and IADL-limitations after 10 years

\begin{tabular}{|c|c|c|c|c|c|c|}
\hline & \multicolumn{3}{|c|}{ Males } & \multicolumn{3}{|c|}{ Females } \\
\hline & OR & $95 \% \mathrm{Cl}$ & $P$-value & OR & $95 \% \mathrm{Cl}$ & $P$-value \\
\hline \multicolumn{7}{|l|}{ Model Ia } \\
\hline Constant & 0.13 & $0.08 ; 0.19$ & 0.000 & 0.42 & $0.31 ; 0.58$ & 0.000 \\
\hline Fatigue & 3.13 & $1.52 ; 6.45$ & 0.002 & 2.25 & $1.27 ; 3.96$ & 0.005 \\
\hline \multicolumn{7}{|l|}{ Model $2^{b}$} \\
\hline Constant & 0.00 & $0.00 ; 0.01$ & 0.000 & 0.00 & $0.00 ; 0.00$ & 0.000 \\
\hline Fatigue & 4.73 & $2.02 ; 11.05$ & 0.000 & 2.22 & $1.21 ; 4.06$ & 0.010 \\
\hline Age & 1.13 & I.08; I.18 & 0.000 & 1.21 & I.I3; I.31 & 0.000 \\
\hline \multicolumn{7}{|l|}{ Model 3c } \\
\hline Constant & 0.00 & $0.00 ; 0.00$ & 0.000 & 0.00 & $0.00 ; 0.00$ & 0.015 \\
\hline Fatigue & 3.29 & $1.95 ; 5.55$ & 0.023 & 1.65 & $0.83 ; 3.26$ & 0.154 \\
\hline Age & 1.15 & I.12; 1.18 & 0.000 & 1.21 & I.12; 1.32 & 0.000 \\
\hline BMI & 1.06 & $0.94 ; 1.20$ & 0.371 & 1.12 & I.04; 1.20 & 0.003 \\
\hline Education & 0.72 & $0.33 ; 1.53$ & 0.388 & 1.76 & I.10; 2.83 & 0.019 \\
\hline Marital status & 4.23 & $2.77 ; 6.45$ & 0.001 & 1.16 & $0.75 ; 1.80$ & 0.498 \\
\hline Chronic disease & 1.82 & I.I8; 2.80 & 0.007 & 1.13 & $0.98 ; 1.30$ & 0.378 \\
\hline MMSE & 0.92 & $0.67 ; 1.28$ & 0.624 & 0.92 & $0.77 ; 1.10$ & 0.363 \\
\hline Lifestyle (baseline) & 1.62 & $0.69 ; 3.81$ & 0.266 & 1.31 & $0.69 ; 2.49$ & 0.418 \\
\hline IADL-limitations (baseline) & 2.13 & $1.53 ; 2.98$ & 0.024 & 2.50 & $0.98 ; 6.35$ & 0.055 \\
\hline Follow-up time & 1.16 & $1.06 ; 1.28$ & 0.002 & 1.02 & $0.93 ; 1.12$ & 0.707 \\
\hline
\end{tabular}

Notes: aCrude; badjusted for age; cadditionally adjusted for BMI, education, marital status, chronic disease, MMSE, lifestyle (activity), baseline IADL-limitations (HAQ), followup time.

Abbreviations: BMI, body mass index; Cl, confidence interval; HAQ, Stanford Health Assessment Questionnaire; IADL, instrumental activities of daily living; MMSE, MiniMental State Examination; OR, odds ratio.

Therefore, a gender-specific analysis was performed to account for this difference. Furthermore, we were unable to differentiate between different dimensions of fatigue such as emotional, mental, or physical exhaustion because only one question on fatigue was measured. In turn, in clinical practice short and concise questions are relevant to screen for possible deficits followed by a comprehensive evaluation if the screening is positive. 2) Fatigue was operationalized by asking participants about their feeling of tiredness. Translation of the concept of fatigue to other languages has

Table 3 Association between fatigue at baseline and mobility performance after 10 years

\begin{tabular}{|c|c|c|c|c|c|c|}
\hline & \multicolumn{3}{|l|}{ Males } & \multicolumn{3}{|l|}{ Females } \\
\hline & B & $95 \% \mathrm{Cl}$ & $P$-value & B & $95 \% \mathrm{Cl}$ & $P$-value \\
\hline \multicolumn{7}{|l|}{ Model I ${ }^{a}$} \\
\hline Constant & 516.91 & $499.02 ; 534.79$ & 0.000 & 421.09 & $397.27 ; 444.91$ & 0.000 \\
\hline Fatigue & -37.97 & $-81.05 ; 5.12$ & 0.084 & -36.16 & $-85.89 ;$ । 3.57 & 0.145 \\
\hline \multicolumn{7}{|l|}{ Model $2^{\mathrm{b}}$} \\
\hline Constant & 849.17 & 769.03; 929.31 & 0.000 & 964.30 & $608.53 ; 1,320.07$ & 0.000 \\
\hline Fatigue & -48.58 & $-87.48 ;-9.68$ & 0.015 & -33.53 & $-83.24 ; 16.18$ & 0.174 \\
\hline Age & -5.67 & $-7.03 ;-4.31$ & 0.000 & -8.28 & $-|3.85 ;-2.7|$ & 0.005 \\
\hline \multicolumn{7}{|l|}{ Model $3^{c}$} \\
\hline Constant & 658.31 & $205.25 ;$ I, III.38 & 0.005 & I, II 6.83 & $214.86 ; 2,018.80$ & 0.017 \\
\hline Fatigue & -39.12 & $-77.83 ;-0.4 \mid$ & 0.048 & -17.46 & $-67.90 ; 32.98$ & 0.479 \\
\hline Age & -5.15 & $-6.61 ;-3.70$ & 0.000 & -7.97 & $-13.61 ;-2.33$ & 0.008 \\
\hline $\mathrm{BMI}$ & -3.36 & $-7.57 ; 0.86$ & 0.118 & -4.85 & $-9.29 ;-0.40$ & 0.034 \\
\hline Education & 13.26 & $-15.96 ; 42.47$ & 0.365 & 12.70 & $-13.03 ; 38.42$ & 0.331 \\
\hline Marital status & -18.12 & $-42.94 ; 6.71$ & 0.152 & 2.82 & $-20.66 ; 26.30$ & 0.813 \\
\hline Chronic disease & -20.28 & $-41.63 ; 1.07$ & 0.062 & -3.88 & $-20.68 ;|2.9|$ & 0.644 \\
\hline MMSE & 8.36 & $-3.94 ; 20.67$ & 0.179 & 5.60 & $-6.92 ; 18.12$ & 0.365 \\
\hline Lifestyle (baseline) & -11.90 & $-40.92 ; 17.13$ & 0.422 & -2.57 & $-49.85 ; 44.71$ & 0.910 \\
\hline Follow-up time & 0.17 & $-3.03 ; 3.37$ & 0.917 & -1.68 & $-8.23 ; 4.91$ & 0.602 \\
\hline
\end{tabular}

Notes: aCrude; badjusted for age; cadditionally adjusted for BMI, education, marital status, chronic disease, MMSE, lifestyle (activity), and follow-up time. Abbreviations: $\mathrm{BMI}$, body mass index; $\mathrm{Cl}$, confidence interval; MMSE, Mini-Mental State Examination. 
been recognized as a challenging entity, ${ }^{40,41}$ and the Dutch translation of tiredness may not capture all facets of the English word fatigue. However, subjective fatigue refers to the general sensation of tiredness, ${ }^{42}$ and as such tiredness is commonly used to operationalize fatigue. ${ }^{18,40} 3$ ) Due to only one follow-up measurement after 10 years we were unable to perform a time-to-event analysis, and important events during follow-up might have been missed. In addition, we were unable to adjust for pain and depression, two known factors associated with fatigue and disability. ${ }^{43,44} 4$ ) The choice of the 6MWT to assess mobility may have influenced the results as participants who did not fulfill the test criteria (ie, high blood pressure) had to be excluded even though they physically may have well been capable to carry out the test as such, but were withheld from performance based on current guidelines. However, analysis of the data with imputed values for these participants did not change the relationship (data not shown). Even though the 6MWT only tests one aspect of mobility it has proven to be a valid and reliable tool of mobility assessment in different populations and is easy to administer in daily practice..$^{32-34}$ To be able to walk for 6 minutes may also be the time needed to walk from home to the supermarket and therefore be an indication whether an individual is able to perform certain tasks of daily living and other daily life activities that are important for independence. Therefore, we deliberately chose for a relatively simple aspect of mobility as an indicator of mobility easily applicable in daily practice. If this aspect of mobility is affected, more in-depth evaluation is necessary like testing endurance and capacity. Furthermore, we were unable to adjust for baseline mobility performance as the 6MWT was not part of the baseline testing battery. As a consequence, we cannot draw any conclusions on the individual trajectory of mobility performance throughout the 10 -year period.

Strengths of the present study are the high percentage of participation (66.6\%) after 10-year follow-up. Moreover, the inclusion of middle-aged and elderly individuals independent of disability status at baseline enables to assess subtle symptoms at an early stage and at relatively young age that is crucial for developing timely interventions to prevent or delay the debilitating process. In addition, a broad concept of functioning (IADL and mobility) was used, which is important for older adults to maintain independence. A long follow-up time of 10 years enabled detection of risk factors at an early stage of the disabling process. Furthermore, IADLs were chosen over basic ADLs as IADL-limitations often precede basic ADL-limitations, ${ }^{45}$ and are considered more complex, and require the ability to make decisions and to interact with the environment. ${ }^{46}$ Finally, the imputation of missing values by multiple imputation which has proven to provide better estimates than complete case analyses, ${ }^{47,48}$ and the questions used to assess fatigue, which are easily applicable in daily practice are additional arguments in favor of the study.

In the present study, both males and females with fatigue were less physically active at baseline and walked a shorter distance within 6 minutes at 10-year follow-up. These findings are in-line with a recent cross-sectional study that found that fatigued individuals performed about 1,150 fewer steps per day and were less physically active compared to those not fatigued. ${ }^{49}$

In our data, fatigue at baseline was significantly associated with IADL-limitations and mobility performance in males, but not in females. This is in contrast with other studies that found a significant relationship between fatigue and IADL-limitations and/or deteriorated mobility in both genders. ${ }^{9,14,16-19}$ However, previous studies indicating a significant relationship had either a cross-sectional design or a shorter follow-up time than the present study. ${ }^{9,14-18,20}$ Moreover, in our study, the association between fatigue and IADL-limitations was statistically significant in the crude and age-adjusted model in females but became statistically non-significant in the fully adjusted model suggesting that factors other than fatigue influence IADL-limitations. The choice of confounders and potentially residual confounding of previous studies could be an additional explanation why our results differ from others. A further explanation for the associations not being statistically significant could be a lack of power in females due to the smaller sample size and weaker associations compared to males. In addition, the assessment of fatigue was based on a single question of an overall feeling of fatigue, whereas other studies used multiple-item questionnaires or assessed the level of fatigue after the performance of specific activities. ${ }^{9}, 14-16,18,20$

The prevalence of fatigue was higher in females $(28.1 \%)$ than in males $(18.6 \%)$, which is in accordance with the literature. Gender-specific prevalence of fatigue ranges from $11.5 \%$ to $46.6 \%$ in females and $6.5 \%$ to $38.0 \%$ in males, ${ }^{19,49}$ although no gender difference ( $49 \%$ in males vs $53 \%$ in females) was measured in the actual performance of daily activities. ${ }^{9}$ The latter was not assessed in the present study. Furthermore, one should mention that the reporting and perception of symptoms between males and females varies $^{50-52}$ between more symptom reporting in females than in males ${ }^{50,53}$ to no gender differences noted. ${ }^{52}$ Concerning the reporting of fatigue, a study on gender differences found that among females only biological complaints and psychosocial 
problems were related to fatigue, whereas in males having a severe handicap and severe chronic complaints were related to fatigue. ${ }^{51}$ These gender-specific differences could be another explanation why we did not find an association between fatigue and functional limitations in females as their perception of fatigue may have been more related to biological and psychosocial problems, entities not assessed in the present study, whereas in males the functional aspect of fatigue symptoms may have been more related to the outcome measures assessed in this study. Our data also points toward a gender-related difference in the effect of fatigue on IADL-limitations and mobility performance. Additional longitudinal studies are needed to elucidate gender-specific differences but should also investigate the multiple dimensions of fatigue and its long-term effect on functioning.

The results of the present study suggest that a single/ unidimensional item self-reported assessment of fatigue may not be sensitive enough as a long-term indicator for IADLlimitations and mobility performance in female middle-aged and older adults. Recently, the concept of fatigability, the assessment of self-reported fatigue after exercise or the performance of specific tasks, has been introduced. ${ }^{12}$ This concept takes the activity context associated with fatigue into account and may provide more insight in activities that cause physical exhaustion. Future studies should determine whether the concept of fatigability is a more appropriate tool to assess fatigue and long-term disability.

\section{Conclusion}

Our data suggest that self-reported non-task-specific fatigue may be a long-term risk factor for IADL-limitations and mobility performance among middle-aged and older males but possibly not in females. Future research should include multiple time measurements and further specify the genderspecific trajectory of IADL-limitations and mobility performance in relation to gender.

\section{Acknowledgments}

The authors gratefully acknowledge all participating older people in the Utrecht area.

The PROFIEL-study was funded by ZonMw, the Netherlands organization for health research and development, grant number 60-61900-98-146. The funding organization played no role in design and conduct of the study, data collection, management, analysis, and interpretation of the data nor in the preparation, review, or approval of the manuscript.

\section{Author contributions}

NB, MJS, and YTvdS designed the study and obtained the funding. SM-S cleaned the data and conducted the clinical analyses. All authors contributed toward data analysis, drafting and revising the paper and agree to be accountable for all aspects of the work.

\section{Disclosure}

The authors report no conflict of interest in this work.

\section{References}

1. Kenter EG, Okkes IM, Oskam SK, Lamberts H. Tiredness in Dutch family practice. Data on patients complaining of and/or diagnosed with “tiredness". Fam Pract. 2003;20(4):434-440.

2. Meng H, Hale L, Friedberg F. Prevalence and predictors of fatigue in middle-aged and older adults: evidence from the health and retirement study. J Am Geriatr Soc. 2010;58(10):2033-2034.

3. Fried LP, Tangen CM, Walston J, et al. Frailty in older adults: evidence for a phenotype. J Gerontol A Biol Sci Med Sci. 2001;56(3): M146-M156.

4. Morley JE, Malmstrom TK, Miller DK. A simple frailty questionnaire (FRAIL) predicts outcomes in middle aged African Americans. J Nutr Health Aging. 2012;16(7):601-608.

5. Solano JP, Gomes B, Higginson IJ. A comparison of symptom prevalence in far advanced cancer, AIDS, heart disease, chronic obstructive pulmonary disease and renal disease. J Pain Symptom Manage. 2006; 31(1):58-69.

6. Hardy SE, Studenski SA. Qualities of fatigue and associated chronic conditions among older adults. J Pain Symptom Manage. 2010;39(6): 1033-1042.

7. Walker EA, Katon WJ, Jemelka RP. Psychiatric disorders and medical care utilization among people in the general population who report fatigue. J Gen Intern Med. 1993;8(8):436-440.

8. Eldadah BA. Fatigue and fatigability in older adults. PMR. 2010;2(5): 406-413.

9. Schultz-Larsen K, Avlund K. Tiredness in daily activities: a subjective measure for the identification of frailty among non-disabled communityliving older adults. Arch Gerontol Geriatr. 2007;44(1):83-93.

10. Kroenke K. A practical and evidence-based approach to common symptoms: a narrative review. Ann Intern Med. 2014;161(8): 579-586.

11. Shahid A, Shen J, Shapiro CM. Measurements of sleepiness and fatigue. J Psychosom Res. 2010;69(1):81-89.

12. Zengarini E, Ruggiero C, Perez-Zepeda MU, et al. Fatigue: relevance and implications in the aging population. Exp Gerontol. 2015;70:78-83.

13. Simonsick EM, Schrack JA, Glynn NW, Ferrucci L. Assessing fatigability in mobility-intact older adults. J Am Geriatr Soc. 2014;62(2): 347-351.

14. Soares WJ, Lima CA, Bilton TL, Ferrioli E, Dias RC, Perracini MR. Association among measures of mobility-related disability and selfperceived fatigue among older people: a population-based study. Braz J Phys Ther. 2015;19(3):194-200.

15. Vestergaard S, Nayfield SG, Patel KV, et al. Fatigue in a representative population of older persons and its association with functional impairment, functional limitation, and disability. J Gerontol A Biol Sci Med Sci. 2009;64(1):76-82.

16. Fagerstrom C, Persson H, Holst G, Hallberg IR. Determinants of feeling hindered by health problems in daily living at 60 years and above. Scand J Caring Sci. 2008;22(3):410-421.

17. Manty M, de Leon CF, Rantanen T, et al. Mobility-related fatigue, walking speed, and muscle strength in older people. J Gerontol A Biol Sci Med Sci. 2012;67(5):523-529. 
18. Gill TM, Desai MM, Gahbauer EA, Holford TR, Williams CS. Restricted activity among community-living older persons: Incidence, precipitants, and health care utilization. Ann Intern Med. 2001;135(5):313-321.

19. Hardy SE, Studenski SA. Fatigue and function over 3 years among older adults. J Gerontol A Biol Sci Med Sci. 2008;63(12):1389-1392.

20. Avlund K, Rantanen T, Schroll M. Tiredness and subsequent disability in older adults: the role of walking limitations. J Gerontol A Biol Sci Med Sci. 2006;61(11):1201-1205.

21. Lebrun CE, van der Schouw YT, Bak AA, et al. Arterial stiffness in postmenopausal women: determinants of pulse wave velocity. J Hypertens. 2002;20(11):2165-2172.

22. Muller M, Grobbee DE, Aleman A, Bots M, van der Schouw YT. Cardiovascular disease and cognitive performance in middle-aged and elderly men. Atherosclerosis. 2007;190(1):143-149.

23. den Ouden ME, Schuurmans MJ, Mueller-Schotte S, Brand JS, van der Schouw YT. Domains contributing to disability in activities of daily living. J Am Med Dir Assoc. 2013;14(1):18-24.

24. UNESCO. Institute of Statistics. International Classification of Education ISCED; 2011 [Updated 2012]. Available from: http://www. uis.unesco.org/Education/Documents/isced-2011-en.pdf. Accessed January 14, 2014.

25. Folstein MF, Folstein SE, McHugh PR. "Mini-mental state". A practical method for grading the cognitive state of patients for the clinician. J Psychiatr Res. 1975;12(3):189-198.

26. Voorrips LE, Ravelli AC, Dongelmans PC, Deurenberg P, Van Staveren WA. A physical activity questionnaire for the elderly. Med Sci Sports Exerc. 1991;23(8):974-979.

27. Bruce B, Fries JF. The Stanford Health Assessment Questionnaire: a review of its history, issues, progress, and documentation. $J$ Rheumatol. 2003;30(1):167-178.

28. Weinberger M, Samsa GP, Schmader K, Greenberg SM, Carr DB, Wildman DS. Comparing proxy and patients' perceptions of patients' functional status: results from an outpatient geriatric clinic. $J$ Am Geriatr Soc. 1992;40(6):585-588.

29. Lutomski JE, van Exel NJ, Kempen GI, et al. Validation of the carerelated quality of life instrument in different study settings: findings from the older persons and informal caregivers survey minimum DataSet (TOPICS-MDS). Qual Life Res. 2015;24(5):1281-1293.

30. van den Brink D, Lutomski JE, Qin L, et al. TOPICS-MDS: a versatile resource for generating scientific and social knowledge for elderly care. Tijdschr Gerontol Geriatr. 2015;46(2):78-91.

31. Graham JE, Ostir GV, Fisher SR, Ottenbacher KJ. Assessing walking speed in clinical research: a systematic review. J Eval Clin Pract. 2008;14(4):552-562.

32. Solway S, Brooks D, Lacasse Y, Thomas S. A qualitative systematic overview of the measurement properties of functional walk tests used in the cardiorespiratory domain. Chest. 2001;119(1):256-270.

33. Steffen TM, Hacker TA, Mollinger L. Age- and gender-related test performance in community-dwelling elderly people: six-minute walk test, berg balance scale, timed up \& go test, and gait speeds. Phys Ther. 2002;82(2):128-137.

34. van Bloemendaal M, van de Water AT, van de Port IG. Walking tests for stroke survivors: a systematic review of their measurement properties. Disabil Rehabil. 2012;34(26):2207-2221.

35. ATS Committee on Proficiency Standards for Clinical Pulmonary Function Laboratories. ATS statement: guidelines for the six-minute walk test. Am J Respir Crit Care Med. 2002;166(1):111-117.
36. Jarosz PA, Davis JE, Yarandi HN, et al. Obesity in urban women: associations with sleep and sleepiness, fatigue and activity. Womens Health Issues. 2014;24(4):e447-e454.

37. Rist PM, Marden JR, Capistrant BD, Wu Q, Glymour MM. Do physical activity, smoking, drinking, or depression modify transitions from cognitive impairment to functional disability? J Alzheimers Dis. 2015; 44(4):1171-1180

38. Lee Y, Kim J, Back JH, Kim S, Ryu M. Changes in combined lifestyle risks and disability transition in older adults: Korean longitudinal study of aging, 2006-2008. Prev Med. 2013;56(2):124-129.

39. Avlund K, Vass M, Hendriksen C. Onset of mobility disability among community-dwelling old men and women. The role of tiredness in daily activities. Age Ageing. 2003;32(6):579-584.

40. Avlund K. Fatigue in older adults: an early indicator of the aging process? Aging Clin Exp Res. 2010;22(2):100-115.

41. Lerdal A, Wahl A, Rustoen T, Hanestad BR, Moum T. Fatigue in the general population: a translation and test of the psychometric properties of the norwegian version of the fatigue severity scale. Scand J Public Health. 2005;33(2):123-130.

42. Lou JS. Physical and mental fatigue in Parkinson's disease: epidemiology, pathophysiology and treatment. Drugs Aging. 2009;26(3):195-208.

43. Manty M, Rantanen T, Era P, Avlund K. Fatigue and depressive symptoms in older people. J Appl Gerontol. 2014;33(4):505-514.

44. Creavin ST, Dunn KM, Mallen CD, Nijrolder I, van der Windt DA. Co-occurrence and associations of pain and fatigue in a community sample of Dutch adults. Eur J Pain. 2010;14(3):327-334.

45. Millan-Calenti JC, Tubio J, Pita-Fernandez S, et al. Prevalence of functional disability in activities of daily living (ADL), instrumental activities of daily living (IADL) and associated factors, as predictors of morbidity and mortality. Arch Gerontol Geriatr. 2010;50(3):306-310.

46. Judge JO, Schechtman K, Cress E. The relationship between physical performance measures and independence in instrumental activities of daily living. The FICSIT group. Frailty and injury: cooperative studies of intervention trials. J Am Geriatr Soc. 1996;44(11):1332-1341.

47. Edwards JK, Cole SR, Troester MA, Richardson DB. Accounting for misclassified outcomes in binary regression models using multiple imputation with internal validation data. Am J Epidemiol. 2013;177(9):904-912.

48. van der Heijden, Donders AR, Stijnen T, Moons KG. Imputation of missing values is superior to complete case analysis and the missingindicator method in multivariable diagnostic research: a clinical example. J Clin Epidemiol. 2006;59(10):1102-1109.

49. Egerton T, Chastin SF, Stensvold D, Helbostad JL. Fatigue may contribute to reduced physical activity among older people: an observational study. J Gerontol A Biol Sci Med Sci. 2015;71(5):670-676.

50. Ladwig KH, Marten-Mittag B, Formanek B, Dammann G. Gender differences of symptom reporting and medical health care utilization in the German population. Eur J Epidemiol. 2000;16(6):511-518.

51. Bensing JM, Hulsman RL, Schreurs KM. Gender differences in fatigue: Biopsychosocial factors relating to fatigue in men and women. Med Care. 1999;37(10):1078-1083.

52. Gili M, Castro A, Navarro C, et al. Gender differences on functioning in depressive patients. J Affect Disord. 2014;166:292-296.

53. Kockler M, Heun R. Gender differences of depressive symptoms in depressed and nondepressed elderly persons. Int J Geriatr Psychiatry. 2002;17(1):65-72.
Clinical Interventions in Aging

\section{Publish your work in this journal}

Clinical Interventions in Aging is an international, peer-reviewed journa focusing on evidence-based reports on the value or lack thereof of treatments intended to prevent or delay the onset of maladaptive correlates of aging in human beings. This journal is indexed on PubMed Central, MedLine,

\section{Dovepress}

CAS, Scopus and the Elsevier Bibliographic databases. The manuscript management system is completely online and includes a very quick and fair peer-review system, which is all easy to use. Visit http://www.dovepress. com/testimonials.php to read real quotes from published authors. 